\title{
How Is the Autonomic Nerve Function Different Between Gastroesophageal Reflux Disease Alone and Gastroesophageal Reflux Disease With Diabetes Mellitus Neuropathy?: Author's Reply
}

TO THE EDITOR: We appreciate Dr. Ke for her comments ${ }^{1}$ on our paper. ${ }^{2}$

In our study, we evaluated only peripheral neuropathy instead of autonomic neuropathy with needle electromyography. Peripheral neuropathy is a common complication of type II diabetes mellitus (DM) and is commonly investigated with electromyography in many diabetes clinics. Autonomic neuropathy, as assessed by cardiovascular autonomic function, is known to be closely associated with symptoms and signs of diabetic peripheral neuropathy. ${ }^{3}$ Patients with peripheral neuropathy, reflected by reduced nerve conduction velocity, have high possibility of cardiovascular autonomic dysfunction in diabetics.

Pathogenesis of gastroesophageal reflux disease (GERD) is multifactorial and not fully understood yet. Transient lower esophageal sphincter relaxation which is controlled through vagal activity $^{4}$ is known to be the most important pathogenetic mechanism of GERD. Some studies suggested that transient lower esophageal sphincter relaxation is found more frequently in diabetics $^{5,6}$ and this can be an explanation how gastroesophageal reflux is related to the autonomic neuropathy in DM. Autonomic nerve dysfunction is presumed to be a major contributory factor for the development of GERD in DM.

However, there have been other observations that have challenged the dominant role of autonomic neuropathy in the etiology of gastrointestinal symptoms in DM. ${ }^{7-9} \mathrm{Jackson}$ et $\mathrm{al}^{9}$ showed in a study on gastric electrical activity and autonomic function among diabetic and non-diabetic patients with symptoms of gastroesophageal reflux that diabetics frequently had normal 24 hour $\mathrm{pH}$ and abnormal autonomic functioning, in contrast to non-diabetics who had abnormal 24 hour $\mathrm{pH}$ and normal autonomic function.
We agree with Dr. Ke's opinion that autonomic nerve function may be one of the contributing factors to the pathogenesis of GERD in cases without DM. However, we have no data at this stage to find any difference between the effects of autonomic neuropathies from non-DM and DM on the pathogenesis and clinical pictures of GERD. We hope that this question could be answered in the future after meticulous studies specifically focused on this point.

Once again, we were very happy with Dr. Ke's interests in our paper.

\section{Sehe Dong Lee, Bora Keum, Hoon Jai Chun and Young-Tae Bak Department of Internal Medicine Korea University Medical Center, Seoul, Korea}

1. Ke M. How is the autonomic nerve function different between gastroesophageal reflux disease alone and gastroesophageal reflux disease with diabetes mellitus neuropathy? J Neurogastroenterol Motil 2011;17:430-431.

2. Lee SD, Keum B, Chun HJ, Bak YT. Gastroesophageal reflux disease in type II diabetes mellitus with or without peripheral neuropathy. J Neurogastroenterol Motil 2011;17:274-278.

3. Lluch I, Hernández A, Real JT, et al. Cardiovascular autonomic neuropathy in type 1 diabetic patients with and without peripheral neuropathy. Diabetes Res Clin Pract 1998;42:35-40.

4. Young RJ, Zhou YQ, Rodriguez E, Prescott RJ, Ewing DJ, Clarke $\mathrm{BF}$. Variable relationship between peripheral somatic and autonomic neuropathy in patients with different syndromes of diabetic polyneuropathy. Diabetes 1986;35:192-197.

5. Lluch I, Ascaso JF, Mora F, et al. Gastroesophageal reflux in diabetes mellitus. Am J Gastroenterol 1999;94:919-924.

6. Dobrek L, Nowakowski M, Mazur M, Herman RM, Thor PJ. Disturbances of the parasympathetic branch of the autonomic nervous system in patients with gastroesophageal reflux disease (GERD) estimated by short-term heart rate variability recordings. J Physiol Pharmacol, 2004;55(suppl 2):77-90. 
7. Ko GT, Chan WB, Chan JC, Tsang LW, Cockram CS. Gastrointestinal symptoms in Chinese patients with type 2 diabetes mellitus. Diabet Med 1999;16:670-674.

8. Clouse RE, Lustman PJ. Gastrointestinal symptoms in diabetic patients: lack of association with neuropathy. Am J Gastroenterol 1989;84:868-872.

9. Jackson AL, Rashed H, Cardoso S, et al. Assessment of gastric elec- trical activity and autonomic function among diabetic and non-diabetic patients with symptoms of gastroesophageal reflux. Dig Dis Sci 2000;45:1727-1730.

\section{Conflicts of interest: None.}

